\title{
Patient Safety Culture: From Perception to Assessment
}

\author{
Ana Cláudia de Brito Passos ${ }^{1, *}$, Djanilson Barbosa dos Santos², Marta Maria de França Fonteles ${ }^{1}$ \\ 'Federal University of Ceará, Faculty of Pharmacy, Dentistry and Nursing, Department of Pharmacy, Graduate Program in Pharmaceutical Sciences, \\ Fortaleza, Ceará, BRAZIL. \\ ${ }^{2}$ Federal University of Reconcavo da Bahia, Health Sciences Center, Santo Antônio de Jesus, Bahia, BRAZIL.
}

\begin{abstract}
Introduction: The patient safety culture constitutes the basis for the development of safe processes and better outcomes for the patients, as it favors the implementation of safe practices. Objectives: The present study aims to assess the patient safety culture in the perception of a multidisciplinary team. Methods: This was a quantitative and qualitative cross-sectional study with 284 professionals who answered the Hospital Survey on Patient Safety Culture questionnaire adapted to Brazil, which measures 12 safety culture dimensions. The reliability of the instrument was verified by the Cronbach's Alpha coefficient. The dependent variables were the percentages of positive answers to estimate strengths and weaknesses in each dimension. EpiData 3.1, the Stata 14.2 software and IRAMUTEQ 0.7.2.0 were used for data processing. Results: The dimensions best assessed were "Supervisor/Manager expectations and actions promoting patient safety" (68.0\%) and "Organizational learning and continuous improvement" (67.0\%). The aspects requiring improvements were "Non-punitive response to error" (20.0\%) and "Staffing" (31.0\%). Other organizational weaknesses were identified from the comments regarding
\end{abstract}

infrastructure, work processes and management support, which can have repercussions in the adoption of the safe practices. In this study, Cronbach's Alpha presented a global value of 0.60 . The "time working in the profession" variable ( $p$-value $=0.033$ ) presented an association with the "overall patient safety grade"; whereas "age" ( $p=0.004)$ was associated with "number of adverse events in the last year." Conclusion: The findings indicate the need for changes in the patient safety culture and in organizational management. Key words: Patient Safety, Organizational Culture, Attitudes and Practice in Health, Quality of Health Care, Hospital Services.

\section{Correspondence}

Ana Cláudia de Brito Passos,

Faculty of Pharmacy, Dentistry and Nursing, Department of Pharmacy. Fortaleza, Ceará, BRAZIL.

Email id: claudiab@ufc.br

DOI: 10.5530/jyp.2021.13.59

\section{INTRODUCTION}

Patient Safety (PS) constitutes a global public health concern, due to its significant impacts, mainly in the hospital context, on the patients' morbidity and mortality, on the high care-related costs involved, and on the suffering of families and professionals. In addition, PS has an impact on the credibility of the health services, affecting their image in society. ${ }^{1}$ Given this scenario, international ${ }^{2}$ and national ${ }^{3}$ initiatives have been implemented with the objective of providing more qualified health care. However, this can only be achieved by strengthening the Patient Safety Culture (PSC), because health care professionals are more likely to work more cooperatively when this culture is a priority in the institutions.

The PSC of an organization is the "product of the individual and group values that reflects the attitudes, perceptions and practices that determine the extent to which the institution prioritizes PS and what safety-related attitudes and behaviors are valued, supported, and expected".

Among the several tools developed to assess the PSC, one of the most widely used is the Hospital Survey on Patient Safety Culture (HSOPSC), created by the US Agency for Healthcare Research and Quality (AHRQ). ${ }^{4}$ The HSOPSC is a self-applied survey that includes 42 items formulated as closed questions and used to calculate scores for 12 PSC dimensions ${ }^{4}$. It also includes a comments section with text content, which, to our knowledge, has been analyzed by few studies, ${ }^{5-7}$ especially in the Brazilian hospital scenario.

In this context, the objective of this study was to assess the PSC from the perception of the multi-professional team.

\section{MATERIALS AND METHODS}

\section{Settings and Design}

This is a quantitative and qualitative study, of the survey type, with a multi-professional team from a public hospital in the state of Ceará, which constitutes a medium-sized secondary level unit of the Unified Health System (Sistema Unico de Saúde, SUS) that is a reference health service for eight municipalities. This hospital has 151 beds distributed into the following assistance units: medical, surgical, obstetric, pediatric, and tuberculosis clinics; emergency, and neonatal care. The study was developed in the period from May to August 2018.

\section{Participants}

The study included those professionals with some permanent or temporary contractual relationship with the institution, either related to assistance or to management. Sample size calculation was based on a proportional stratified sampling model. A margin of error of 5\%, a confidence level of $95 \%$, and an response rate of $50 \%$ (probability) ${ }^{4}$ were considered, so the sample size was estimated at 235 individuals within a universe of 601 employees. Visits to the units were conducted in the three shifts and during the weekends, and 400 questionnaires were distributed in order to achieve the established sample size.

\section{Data Collection Instrument and Operationalization}

The translated and validated version of the Hospital Survey on Patient Safety Culture (HSOPSC) ${ }^{8}$ for the Brazilian setting was used. The tool was elaborated to assess the opinions of the hospital team on the PSC. It

This is an open access article distributed under the terms of the Creative Commons Attribution-NonCommercial-ShareAlike 4.0 License, which allows others to remix, tweak, and build upon the work non-commercially, as long as the author is credited and the new creations are licensed under the identical terms. 
includes 42 items that measure 12 PSC dimensions. Most of the items use the 5-point (from I totally disagree to I totally agree) or frequency (never or always) Likert answer scale. ${ }^{8}$

The questionnaire also included a question on the global score of the PS level, a question on the number of safety incidents reported in the last year, and an essay question: "Please feel free to write any comments on patient safety, error, or event notifications in the hospital where you work." After verbal acceptance and signature of the Free and Informed Consent Form (FICF), the professionals who accepted to participate in the study received the data collection instrument, which was returned at the end of the work shift.

\section{Data Analysis}

EpiData 3.1 was used for data entry, and the Stata 14.2 software for analysis. The percentages of positive answers were calculated, and dimensions with $75 \%$ or above of positive answers (agree or totally agree with positively worded items, or disagree or totally disagree with negatively worded items) were considered strong, whereas dimensions with a percentage of positive answers equal to or below $50 \%$ were considered weak, according to the AHRQ recommendations. ${ }^{4}$ Domain reliability was calculated using the Cronbach's Alpha coefficient, which indicates the extent to which the items are related to each PSC dimension and with the full questionnaire.

The Pearson's Chi-Square test was used to explore the associations between socio-professional variables (independent variables) - gender, schooling, professional category, workplace, time working in the hospital, time working in the area, time working in the profession, and age - with the PS level and number of adverse events reported in the last year (dependent variables). For this study, the significance level was considered as $p$-value $\leq 0.05$, for a $95 \%$ confidence interval. Descriptive statistics was used to present the socio-professional characteristics of the respondents; and inferential statistics was used to assess the relationship between the variables.

The comments were fully transcribed and treated to improve data analysis by means of the content analysis technique, with the assessment of the frequency of word repetition supported by the Interface de R pour Analyses Multidimensionnelles de Textes et de Questionneires (IRAMUTEQ) 0.7.2.0 software, which enables understanding the texts by presenting the results in the form of the Descending Hierarchical Classification (DHC) method and similarity analysis. ${ }^{9}$ However, it is emphasized that data interpretation and analysis were based on the pertinent literature related to PS and organizational culture. The professionals who contributed with comments were identified by numbers.

\section{Ethical Aspects}

This study was approved by the Ethics Committee of the Federal University of Ceará (number: 2.402.613) in 2017.

\section{RESULTS}

Of the 400 questionnaires distributed, 284 were returned, yielding a response rate of $71 \%$. The questionnaires retrieved were verified regarding errors and inconsistencies, but all were considered valid for the analyses.

\section{Socio-professional Characteristics of the Participants}

There was predominance of the female gender, with $82.4 \%$. The age group between 31 and 50 years old stood out $(n=148 ; 53.2 \%)$ and the Nursing team represented the majority $(n=157 ; 55.2 \%)$ of the respondents. Most $(n=152 ; 54.0 \%)$ of the participants have a workload between 20 and 39 weekly hours, have worked in the hospital for more than 11 years $(n=103 ; 36.0 \%)$, and $98(34.5 \%)$ have some post-graduate degree. Among the study participants, 67 (23.6\%) work in Obstetrics, 40 (14.0\%) in the Medical Clinic, and 37 (13.0\%) in the Surgical Area. Of the 284 study participants, $252(89.0 \%)$ interacted directly with the patients, according to Table 1 .

\section{Perception of the Respondents on the PSC}

The general PSC level was $47.0 \%$. Of the individual dimensions, "Supervisor/Manager expectations and actions promoting safety" obtained the highest score (68.0\%), followed by "Organizational learning and continuous improvement" (67.0\%). The areas with the greatest improvement potential were "Non-punitive response to error" (20.0\%) and "Staffing" (31.0\%), but other seven dimensions presented values below $50 \%$ and were therefore considered weak areas (Table 2).

In this study, Cronbach's Alpha varied from 0.30 to 0.89 (Table 2), with a global value of 0.60 . The "Frequency of events reported" and "Teamwork within units" dimensions presented the highest coefficients $(0.89$ and 0.77, respectively). Conversely, four dimensions obtained Alpha values below 0.60 ("Staffing", "Overall perception of PS", "Teamwork across units", and "Non-punitive response to error").

\section{Patient Safety Level and Number of Events Reported in the Last Year}

According to this study, $9.0 \%$ and $26.0 \%$ of the interviewees classified PS as "excellent" and as "very good", respectively. However, the majority (56.0\%) considered PS as "acceptable" (Figure 1). In our study, in relation to the number of events reported in the last year, most $(77.0 \%)$ of the interviewees never notified any event/error (Figure 2). By analyzing the percentage of positive answers for the "PS grade" and "Number of events reported in the last 12 months" outcome variables, according to professional category, it was verified that the best grade attributed to PS was "acceptable", distributed among all the professional categories. It is important to highlight that the overall PS grade was considered as "poor/ very poor" by $18.2 \%$ of the nurses; in this category and, if the remaining members of the Nursing team are considered, this value rises to $27.9 \%$.

In relation to the number of reported events, nurses stand out with $29.6 \%$ notifying at least one event in the last year. However, there was no statistically significant difference for any of the outcome dimensions (Table 3). A significant percentage of the Nursing team classified overall PS as "poor/very poor", but there was no statistically significant difference.

An association between the "Overall PS grade" outcome dimension with the following socio-professional variables was also verified: gender $(p$-value $=0.535)$, schooling $(p$-value $=0.018)$, time working in the hospital $(\mathrm{p}$-value $=0.347)$, time working in the sector/area $(p$-value $=0.077)$, and age $(p$-value $=0.245)$, but with no statistically significant difference. However, the time working in the profession $(p$-value $=0.033)$ variable

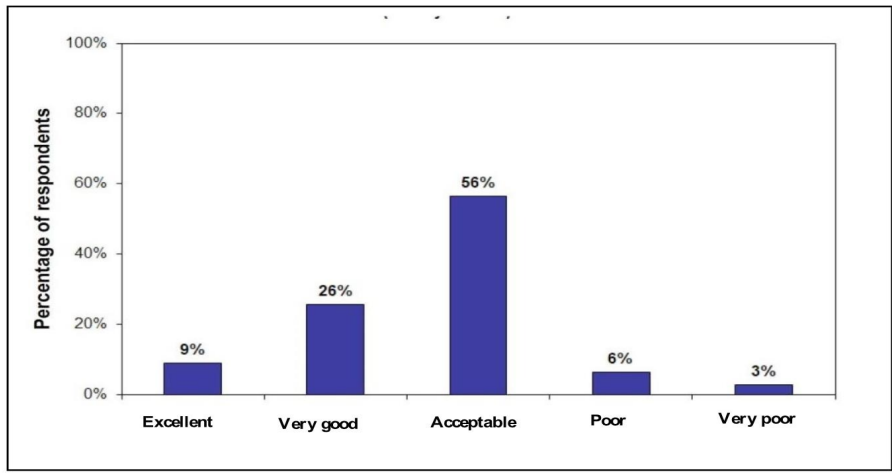

Figure 1: Assessment of the patient safety level, from the perspective of the professionals, Ceara, Brazil, $2019(n=284)$. 
Table 1: Characterization of the study participants, Ceará, Brazil, 2019 ( $n=284)$.

\begin{tabular}{|c|c|c|}
\hline Variables & $\mathrm{n}$ & $\%$ \\
\hline \multicolumn{3}{|l|}{ Gender } \\
\hline Female & 234 & 82.4 \\
\hline Male & 50 & 17.6 \\
\hline Total & 284 & 100.0 \\
\hline \multicolumn{3}{|l|}{ Age } \\
\hline Up to 30 years old & 45 & 16.3 \\
\hline $31-50$ & 148 & 53.2 \\
\hline $51+$ & 83 & 30.0 \\
\hline Absent data & 8 & 0.5 \\
\hline Total & 284 & 100.0 \\
\hline \multicolumn{3}{|l|}{ Schooling Level } \\
\hline Elementary School & 5 & 1.7 \\
\hline High School & 103 & 36.3 \\
\hline Higher Education & 78 & 27.5 \\
\hline Postgraduate Course & 98 & 34.5 \\
\hline Total & 284 & 100.0 \\
\hline \multicolumn{3}{|l|}{ Position/Role in the Hospital } \\
\hline Nursing Technician/Assistant & 113 & 39.7 \\
\hline Nurse & 44 & 15.5 \\
\hline Technicians (Laboratory/Radiology/Pharmacy) & 38 & 13.4 \\
\hline $\begin{array}{l}\text { Administrative (managers and administrative } \\
\text { assistants) }\end{array}$ & 32 & 11.3 \\
\hline Physician & 29 & 10.2 \\
\hline Others (Psychologist, Engineer, Social Worker, & & \\
\hline $\begin{array}{l}\text { Nutritionist, Occupational Therapist, Pharmacist, } \\
\text { Speech Therapist) }\end{array}$ & 28 & 9.9 \\
\hline Total & 284 & 100.0 \\
\hline \multicolumn{3}{|l|}{ Workload, hours } \\
\hline Less than 20 hours a week & 22 & 8.0 \\
\hline 20-39 hours a week & 152 & 54.0 \\
\hline 40-59 hours a week & 105 & 37.0 \\
\hline $60+$ hours a week & 5 & 1.0 \\
\hline Total & 284 & 100.0 \\
\hline \multicolumn{3}{|l|}{ Time working in the area/specialty, years } \\
\hline$\leq 5$ years & 131 & 46.0 \\
\hline $6-10$ years & 81 & 29.0 \\
\hline $11+$ years & 72 & 25.0 \\
\hline Total & 284 & 100.0 \\
\hline \multicolumn{3}{|l|}{ Time working in the hospital, years } \\
\hline$\leq 5$ years & 99 & 35.0 \\
\hline $6-10$ years & 82 & 29.0 \\
\hline $11+$ years & 103 & 36.0 \\
\hline Total & 284 & 100.0 \\
\hline \multicolumn{3}{|c|}{ Time working in your current specialty or profession, years } \\
\hline$\leq 5$ years & 69 & 24.3 \\
\hline $6-10$ years & 72 & 25.3 \\
\hline $11+$ years & 143 & 50.3 \\
\hline Total & 284 & 100.0 \\
\hline \multicolumn{3}{|l|}{ Main working area/unit in the hospital } \\
\hline Obstetrics & 67 & 23.6 \\
\hline Medical Clinic & 40 & 14.0 \\
\hline Surgical Area & 37 & 13.0 \\
\hline Imaging & 30 & 10.6 \\
\hline Clinical Analysis Laboratory & 17 & 6.0 \\
\hline Pediatrics (Pediatric Clinic and Neonatology) & 11 & 4.0 \\
\hline Pharmacy & 10 & 3.4 \\
\hline $\begin{array}{l}\text { Others (Transfusion agency, Emergency, } \\
\text { Tuberculosis, Various hospital units/No specific unit) }\end{array}$ & 72 & 25.4 \\
\hline Total & 284 & 100.0 \\
\hline \multicolumn{3}{|l|}{ Contact status with the patient } \\
\hline Direct contact & 252 & 89.0 \\
\hline No direct contact & 32 & 11.0 \\
\hline Total & 284 & 100.0 \\
\hline
\end{tabular}

did present a statistically significant value, which leads us to infer that the professionals tend to attribute a better grade for PS as years go by.

Regarding the presence of associations between the "Number of adverse events reported in the last 12 months" outcome variable and the following socio-professional variables: gender $(p$-value $=0.785)$, time working in the hospital ( $p$-value $=0.926)$, time working in the sector/area ( $p$-value $=0.841)$, time working in the profession $(p$-value $=0.559)$, and schooling ( $p$-value $=0.159)$, no statistically significant difference was found. However, the age variable $(p$-value $=0.004)$ presented a statistically significant value, suggesting that older professionals tend to report more. This can be related to the fact that these professionals started to attribute more value to this practice as important for PS.

\section{Analysis of the Comments - Subjective Question of the HSOPSC}

Of the participating professionals, 79 contributed with comments, but only 67 (24\%) were analyzed, considering that some of them were illegible, incomprehensible, or were not relevant (such as "No", "Nothing to report", "None").

With the use of IRAMUTEQ and applying the DHC method, 71 text segments (TS) were retrieved, with a utilization rate of $78.02 \%$ of the

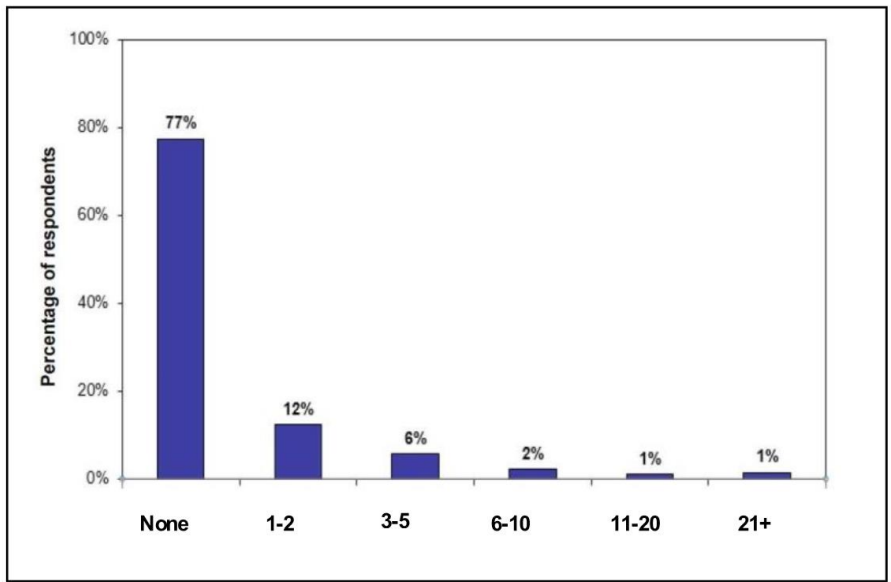

Figure 2: Number of adverse events reported by the professionals in the last 12 months, Ceara, Brazil, 2019 ( $n=284)$.

Class 4

\begin{tabular}{l|}
\hline \multicolumn{1}{|c|}{$29.6 \%$} \\
\hline Notification \\
Relate \\
Situation \\
Conduct \\
Notify \\
Theme \\
Notifier \\
Attitude \\
Mode \\
Limited \\
Involved \\
Event \\
Report \\
Problem \\
Opportunity
\end{tabular}

\begin{tabular}{|l|}
\multicolumn{1}{|c}{ Class3 } \\
\hline \multicolumn{1}{|c}{$23.9 \%$} \\
\hline Patient safety \\
Team \\
Care \\
Attention \\
Notification \\
Good \\
Greater \\
Focus \\
Procedure \\
Information \\
Duty \\
Importance
\end{tabular}

\begin{tabular}{|l|}
\multicolumn{1}{|r}{ Class1 } \\
\hline $23.9 \%$ \\
\hline Safety \\
Surveillance \\
Patient \\
Hospital \\
Employee \\
Need \\
Sector \\
Hospital \\
Flows \\
Work \\
\end{tabular}

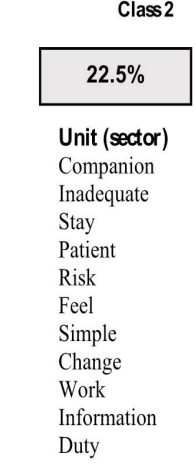

Figure 3: Phylogram (DCH) of the corpus (horizontal in shape) about the representations of the health professionals, obtained from their comments, 2019, organized using the IRAMUTEQ software. 


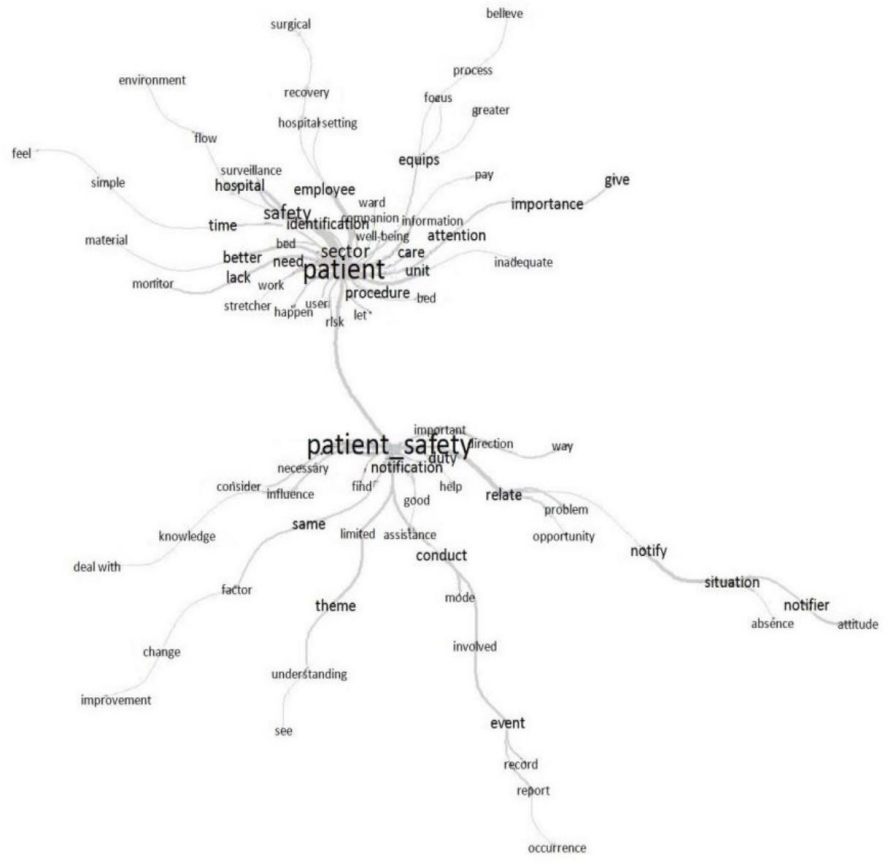

Figure 4: Similarity tree obtained from the comments made by the health professionals, 2019, and organized using the IRAMUTEQ software.

total. The results identified the presence of four different classes (Figure 3), whose names were attributed based on their descriptors, contexts, and theoretical framework.

By analyzing the comments, weaknesses for PS that could explain the low scores obtained for the PSC dimensions were identified, providing us a better view of the current culture and of the factors that can interfere with its improvement.

Class 1, named "Management support" and with 23.9\% of the TS, shows how hospital management favors a work environment that promotes patient safety. The excerpts retrieved delineate this context:

Excerpt 1. [...] there is the need for a greater attention and regular development of actions focusing on continuing education and guidelines to the team in order to enhance the applicability of the preventive routines (Subject 8).

Excerpt 2. [....] Insufficient staffing for the demand, difficulty in releasing the professionals for training sessions and congresses (Subject 41).

Excerpt 3. There is so much to do in all the areas, especially in the critical processes, but I think that the main focus is spreading knowledge on the theme and its importance to the workforce, the high-end team. Unfortunately, we still see a lot that understanding and concern on the theme is basically concentrated on the managers (Subject 31).

Class 2, named "Communication for safe care", totaled $22.5 \%$ of the analyzed corpus, covering aspects such as: communication openness, care transition, and presence of a companion, as shown in the excerpts below: Excerpt 1. [...] There could be more communication between the general coordination and its professionals. It is very unsatisfactory (Subject 2).

Excerpt 2. [...] The physicians lack clarity when providing information to the patients, their family members, and the team. [...] They do not communicate among each other and give contradictory information to the patients. The information provided is often inconsistent with what is recorded in the medical chart [...] (Subject 30).
Table 2: Results of the PSCa level and of the internal reliability of the HSOPSC $^{\mathrm{b}}$, from its dimensions, Ceará, Brazil, 2019 ( $\left.n=284\right)$.

\begin{tabular}{|c|c|c|c|}
\hline PSC a dimensions & $\begin{array}{l}\text { Number } \\
\text { of items }\end{array}$ & $\begin{array}{c}\text { Cronbach's } \\
\text { Alpha }\end{array}$ & $\begin{array}{c}\text { Percentage } \\
\text { of positive } \\
\text { answers }\end{array}$ \\
\hline $\begin{array}{l}\text { 1. Teamwork within } \\
\text { units }\end{array}$ & 4 & 0.77 & 66.0 \\
\hline $\begin{array}{l}\text { 2. Supervisor/Manager } \\
\text { expectations and actions } \\
\text { promoting patient safety }\end{array}$ & 4 & 0.66 & 68.0 \\
\hline $\begin{array}{l}\text { 3. Organizational } \\
\text { learning - continuous } \\
\text { improvement }\end{array}$ & 3 & 0.69 & 67.0 \\
\hline $\begin{array}{l}\text { 4. Management support } \\
\text { for patient safety }\end{array}$ & 3 & 0.67 & 42.0 \\
\hline $\begin{array}{l}\text { 5. Overall perception of } \\
\text { patient safety }\end{array}$ & 4 & 0.32 & 39.0 \\
\hline $\begin{array}{l}\text { 6. Feedback and } \\
\text { communication about } \\
\text { error }\end{array}$ & 3 & 0.76 & 47.0 \\
\hline $\begin{array}{l}\text { 7. Communication } \\
\text { openness }\end{array}$ & 3 & 0.60 & 54.0 \\
\hline $\begin{array}{l}\text { 8. Frequency of events } \\
\text { reported }\end{array}$ & 3 & 0.89 & 48.0 \\
\hline 9. Teamwork across units & 4 & 0.47 & 42.0 \\
\hline 10. Staffing & 4 & 0.30 & 31.0 \\
\hline $\begin{array}{l}\text { 11. Handoffs and } \\
\text { transitions }\end{array}$ & 4 & 0.60 & 42.0 \\
\hline $\begin{array}{l}\text { 12. Non-punitive } \\
\text { response to error }\end{array}$ & 3 & 0.44 & 20.0 \\
\hline $\begin{array}{l}\text { Overall level of the } \\
\text { patient safety culture }\end{array}$ & 42 & 0.60 & 47.0 \\
\hline
\end{tabular}

aPSC: Patient Safety Culture.

bHSOPSC: Hospital Survey on Patient Safety Culture.

Excerpt 3. The transfers [which must be understood as patients' transfer] from the emergency unit to the wards are often conducted in an inappropriate and dangerous way (Subject 42).

Class 3, named "Patient care", accounted for $23.9 \%$ of all the comments and portrayed elements related to the work structure and process, involving infrastructure, use of guiding tools for more effective care, and safe practices. The excerpts below illustrate the understanding of the class content and the context of its elements:

Excerpt 1. Inappropriate floor for the patients who move around; lack of bars on the restroom walls. [...] the balconies of the wards have no protection netting, which makes these units quite unsafe for the patients (Subject 43). Excerpt 2. I believe that the largest risk is the lack of flow charts, SOPs, and well-established protocols based on evidence and discussed together with direct healthcare professionals (Subject 55).

Finally, class 4, named "Risk management", with the highest number of comments (29.6\%), dealt with factors related to the return of information 
Table 3: Comparison of the outcome variables: PS grade and number of events reported in the last year, according to the respondents' professional categories, Ceará, Brazil, 2019 ( $n=284)$.

\begin{tabular}{|c|c|c|c|c|c|c|c|c|c|c|c|c|c|c|}
\hline \multicolumn{2}{|c|}{ Variables } & \multicolumn{2}{|c|}{ Administrative* } & \multicolumn{2}{|c|}{ Nurse } & \multicolumn{2}{|c|}{ Physician } & \multicolumn{2}{|c|}{$\begin{array}{c}\text { Nursing Technicians/ } \\
\text { Assistants }\end{array}$} & \multicolumn{2}{|c|}{ Technicians** } & \multicolumn{2}{|c|}{ Others ${ }^{* * *}$} & \multirow[t]{2}{*}{$p$-value $e^{* * * *}$} \\
\hline & & $\mathrm{n}$ & $\%$ & $\mathrm{n}$ & $\%$ & $\mathrm{n}$ & $\%$ & n & $\%$ & $n$ & $\%$ & $\mathrm{n}$ & $\%$ & \\
\hline \multirow{3}{*}{$\begin{array}{c}\text { Patient } \\
\text { safety }\end{array}$} & $\begin{array}{l}\text { Excellent/ } \\
\text { Very good }\end{array}$ & 13 & 40.6 & 14 & 31.8 & 9 & 31.0 & 42 & 37.2 & 17 & 44.7 & 3 & 10.7 & \multirow[t]{3}{*}{0.048} \\
\hline & Acceptable & 18 & 56.3 & 22 & 50.0 & 18 & 62.1 & 60 & 53.1 & 18 & 47.4 & 24 & 85.7 & \\
\hline & $\begin{array}{c}\text { Poor/ } \\
\text { Very poor }\end{array}$ & 1 & 3.1 & 8 & 18.2 & 2 & 6.9 & 11 & 9.7 & 3 & 7.9 & 1 & 3.6 & \\
\hline \multirow{2}{*}{$\begin{array}{c}\text { Number } \\
\text { of events } \\
\text { reported } \\
\text { in the last } \\
\text { year }\end{array}$} & None & 24 & 75.0 & 31 & 70.5 & & 79.3 & 93 & 82.3 & 31 & 81.9 & 18 & 64.3 & \multirow[b]{2}{*}{0.299} \\
\hline & $\begin{array}{l}\text { More } \\
\text { than } 1\end{array}$ & 8 & 25.0 & 13 & 29.6 & & 20.7 & 20 & 17.7 & 7 & 18.4 & 10 & 35.7 & \\
\hline
\end{tabular}

${ }^{*}$ Administrative: Pharmacy, Laboratory and Imaging

**Technician: managers and administrative assistants.

${ }^{* * *}$ Others: Pharmacist, Physiotherapist, Occupational Therapist, Psychologist, Social Worker.

$\star * * * *$ Pearson's chi-square test, $p$-value $<0.05$.

and communication about errors, non-punitive response to error, and frequency of reported events, according to the excerpts below:

Excerpt 1. [...] the complete absence of feedback on the reported situations and their repetition, I mean their recurrence, are factors that compromise our involvement and lead us to discredit the possibility of changes, of improvements (Subject 65).

Excerpt 2. [...] The professionals are concerned that their errors are reported in their occupational records due to fear of losing their jobs. The frequency of reported events has been reducing because of discredit and even retaliations, the search for the culprit, the look limited to the occurrence, of the directly involved people [...] with no opportunity to reflect and discuss on the reported situation, they are characteristics of the way in which reported events are managed (Subject 67).

By observing the similarity analysis shown in Figure 4, it is noticed that the most frequently cited words were the following: patient and patient safety. The word patient is located in the central axis, with the words sector, care, procedure, well-being, attention, and safety in near branches; and, from the central word patient, an independent branch was generated: patient safety, with the words duty, notification, important, and necessary. Conversely, the words notifier, attitude, improvement, and occurrence are distant from the central axis. In this way, it was possible to infer the structure involved in the construction of the text and of the themes of relative importance, from the professionals' perspective, where the most relevant words: "safety" and "patient safety" and the terms related to them point us to the context where the PSC is inserted in the institution under study, as well as related factors.

\section{DISCUSSION}

The results indicate what relevant aspects of the PSC, an important psychology approach in health care organizations, require further development. However, according to the professionals' perception, the "Supervisor/Manager expectations and actions promoting safety" and "Organizational learning and continuous improvement" dimensions were positive aspects in the organizational culture, although they were not strong areas. ${ }^{4}$ Regarding these dimensions, national ${ }^{10}$ and international ${ }^{11}$ studies found higher results than our findings. It is worth mentioning that teamwork within the unit is also an important dimension in the perception of the professionals participating in the study. This dimension can be the key to exerting positive force on the perception of safety, since a good relationship in the unit and with immediate supervisors/managers can provide efficient support for the promotion of interventions to improve safety within this context.

The dimensions with the greatest improvement potentials were "Non-punitive response to error" and "Staffing". Both dimensions will have a direct impact on the practices performed by the professionals, leading, for example, to a low percentage of notifications in the last year, as found in this study, which can be justified by the professionals' perceptions on the "Non-punitive response to error" dimension. Other studies corroborate these results, ${ }^{12,13}$ since the punitive culture seems to be a common element in hospital environments worldwide, representing a challenge to be overcome for the improvement of the PSC.

It is also worth mentioning that the "Overall perception of PS", "Staffing", "Teamwork across units" and "Non-punitive response to error" dimensions of the HSCOPSC contain reverse items, which represents a strategy implemented by the survey developers ${ }^{4}$ to prevent tendentious answers, as reverse items require greater attention from the respondents. However, according to those who use the HSOPSC, ${ }^{14}$ this ends up leading to difficulties in interpreting these items and thus contributes to the existence of internal consistency problems, which are also associated with cultural differences between the diverse scenarios.

About the patient safety level, this result seems to be contradictory, since there are improvements to be made in several aspects of PS, according to the percentage of positive answers in the PSC dimensions, such as consolidating the practice of reporting, which is considered a good indicator for $\mathrm{PS}^{15}$ and characterizes institutions with a positive PSC.

Regarding the number of events reported in the last year, similar findings were identified in other study. ${ }^{16}$ It is known that nurses are generally responsible for notifying adverse events, considering their profile in both managing the notifications and encouraging the team. However, this role must be performed by all the professionals and not only by one category, because patient safety encompasses a multi-professional team. 
Passos, et al.: A Perspective on the Patient Safety Culture

When institutions have appropriate quantitative and qualitative indicators, care provision is safe. A number of studies ${ }^{12,13}$ assessing the PSC also found similar results, indicating that staff adequacy is a critical problem in most health institutions worldwide. Weaknesses in this aspect can lead to dissatisfaction with the working conditions, excessive and exhausting workdays and stress, which causes unfavorable outcomes for patients and compromises their safety. Another important aspect mentioned by the respondents in this class was the need to expand knowledge on PS to the entire multi-professional team. The human resources practices, together with an active leadership, are elements of organizational management and have an influence on the adoption of safe practices, as well as on safety-related values and behaviors. ${ }^{17}$

The class 2 "Communication for safe care", the emphasis is on communication, either between managers and those led, among the professionals, or during care transitions. Regarding the latter, it is known that sharing information during transitions and handoffs provides useful subsidies for the identification of possible safety problems, either current or imminent, thus being possible to intervene in order to reduce them. All these aspects have already been pointed out as weak in the assessment of the PSC dimensions and are reinforced by the professionals' reports.

About the class 3, named "Patient care", the vulnerabilities in the infrastructure and the precarious use of safety and quality management tools such as protocols, flow charts, and Standard Operating Procedures (SOPs), are not contemplated in the HSOPSC. ${ }^{4}$ Health institutions must adopt safe practices by means of standardized processes, protocols, checklists and guidelines, thus showing their concern in developing such practices, as well as to support evidence-based decision-making. ${ }^{1}$

About the class "Risk management", the analysis of this class enabled a better understanding of the reason for non-reporting by the professionals, which includes fear of retaliations, lack of knowledge about the use of the notification form, and lack of feedback to notifications and complaints, which ends up leading to underreporting. A study conducted in a university hospital in France ${ }^{5}$ found similar results. Return of information and communication about errors in the form of feedback are a "virtuous circle that contributes to the improvement of the organizational culture". ${ }^{18}$ Leaders who are committed to PS consider the practice of reporting as an opportunity for improvement and organizational learning. ${ }^{19}$

It is important to consider that the answers are based on perceptions and can reflect on what the participants believe is happening, but the reality may be different. Another possible limitation is the fact that the subjective question of the HSOPSC may have been answered immediately after filling out items that address the PSC dimensions, which may have induced the professionals to express aspects that had been addressed in the questionnaire.

\section{CONCLUSION}

By means of the assessment, it was possible to identify the main aspects that are related to PS. Based on these aspects, a profile of the PSC was established, as well as its weaknesses and barriers that limit care provision with quality and safety, pointing to the factors that contribute to the strengthening of the local PSC. In this context, for the professionals in question, PS is intimately related to infrastructure, work processes and leadership support.

The findings of this study may also help the governmental health policy makers and hospital managers to understand the related challenges and to develop strategies to improve PS, such as periodic evaluations of the local culture, promoting a sustainable development of the PSC in the institutions. The provision of financial resources would also be a way to encourage improvement actions, by enhancing the quality of the services offered.

\section{ACKNOWLEDGEMENT}

The authors appreciate all the people who have assisted them in conducting this research.

\section{CONFLICT OF INTEREST}

The authors declare no conflict of interest.

\section{REFERENCES}

1. Sousa P, Mendes Walter. Organizadores. Segurança do paciente: criando organizações de saúde seguras. ENSP Fio Cruz. Vol. 2. ISBN: 978-85-8432-0622; $2019^{a}$ ed. Rio de Janeiro. CDEAD. [Citado em; Mar 7 2020].

2. Donaldson Liam J, Fletcher Martin G. The WHOWorld Alliance for Patient Safety: towards the years of living less dangerously. Med J Aust. 2006;184(S10);Suppl 10 [Suppl 69:S69-72]:S69-72. doi: 10.5694/j.1326-5377.2006.tb00367.x, PMID 16719741.

3. Ministério da Saúde (BR). Portaria $n^{\circ}$ 529, de; 2013. Institui o. Programa Nacional de Segurança do Paciente (PNSP). Diário Oficial da União; 1 abril de. Seção; 1:43

4. Sorra JS, Nieva VF. Hospital Survey on Patient safety culture. Rockville: Agency for Healthcare Research and Quality; 2004 [cited 3/8/2021]. Available from: https://www.ahrq.gov/sites/default/files/publications/files/hospcult.pdf

5. Boussat Bastien, Kamalanavin Kevin, François Patrice. The contribution of open comments to understanding the results from the Hospital Survey on Patient Safety Culture (HSOPS): A qualitative study. PLOS ONE. 2018;13(4):e0196089. doi: 10.1371/journal.pone.0196089, PMID 29672577.

6. Atanázio MdGN, De Medeiros AID, Sousa KDM, Gama ZADS, Batista AMSEGURANÇA DO PACIENTE: REPRESENTAÇÃO SOCIAL PARA PROFISSIONAIS DE SAÚDE EM ÂMBITO HOSPITALAR. Infarma. 2019:31(1):34-45 doi: 10.14450/2318-9312.v31.e1.a2019.pp34-45.

7. Batalha da EMS Silva, Melleiro MM. Cultura de segurança do paciente: percepções da equipe de enfermagem. Hu Rev. 2016;2016:42 (2)

8. Reis Claudia Tartaglia, Laguardia Josué, Martins Mônica. Translation and crosscultural adaptation of the Brazilian version of the Hospital Survey on Patient Safety Culture: initial stage. Cad Saude Publica. 2012;28(11):2199-210. doi: 10.1590/S0102-311X2012001100019, PMID 23147961.

9. Camargo BV Justo AM. Tutorial para uso do software de análise textual IRaMuteQ: interface de análise multidimensionais de textos e questionários. Florianópolis: Universidade Federal de Santa Catarina; 2018 [citado Mar 07 2020]. Available from: http://iramuteq.org/documentation/fichiers/tutorielportugais-22-11-2018.

10. Andrade Luiz Eduardo Lima, Lopes Johnnatas Mikael, Souza Marlon César Melo, Vieira Romero Fonseca, Farias Luiz Paulo Costa, Santos Carla Caroline Medeiros Dos, Gama ZADS. Patient safety culture in three Brazilian hospitals with different types of management. Cien Saúde Colet. 2018;23(1):161-72. doi: 10.1590/1413-81232018231.24392015, PMID 29267821.

11. Okuyama Julia Hiromi Hori, Galvao Tais Freire, Silva Marcus Tolentino. Healthcare professional's perception of patient safety measured by the hospital survey on patient safety culture: A systematic review and meta-analysis. ScientificWorldJournal. 2018;2018:9156301. doi: 10.1155/2018/9156301.

12. Andrade LEL, Lopes JM, Souza Filho MCM, Vieira Júnior RF, Farias LPC, Santos CCMD, Gama ZADS. Patient safety culture in three Brazilian hospitals with different types of management. Ciência \& Saúde Coletiva. 2018; 23: 161-172. doi: 10.1590/1413-81232018231.24392015

13. Reis Cláudia Tartaglia, Paiva Sofia Guerra, Sousa Paulo. The patient safety culture: a systematic review by characteristics of Hospital Survey on Patient Safety Culture dimensions. Int J Qual Health Care. 2018;30(9):660-77. doi: 10.1093/ intqhc/mzy080, PMID 29788273.

14. Perneger TV, Staines A, Kundig F. Internal consistency, factor structure and construct validity of the French version of the Hospital Survey on Patient Safety Culture. BMJ Qual Saf. 2014 May; 23 (5): 389-97. doi:10.1136/bmjqs-2013-002024.

15. Reis Cláudia Tartaglia, Laguardia Josué, Vasconcelos Ana Glória Godoi Martins Mônica. Reliability and validity of the Brazilian version of the Hospita Survey on Patient Safety Culture (HSOPSC): a pilot study. Cad Saude Publica. 2016;32(11):e00115614. doi: 10.1590/0102-311X00115614, PMID 27925026.

16. Andrade LEL, Melo LOM, Silva IGD, Souza RM, Lima ALB, Freitas MR, Batista Almária Mariz, Gama ZADS de et al. Adaptation and validation of the Hospital Survey on Patient Safety Culture in an electronic Brazilian version. Epidemiol Serv Saúde. 2017;26(3):455-68. doi: 10.5123/S1679-49742017000300004 PMID 28977171.

17. Singer Sara J, Vogus Timothy J. Reducing hospital errors: interventions that build safety culture. Annu Rev Public Health. 2013;34:373-96. doi: 10.1146/ annurev-publhealth-031912-114439, PMID 23330698.

18. Batista Josemar, Cruz EDA, Alpendre Francine Taporosky, Paixão DPDSSD, Gaspari Ana Paula, Mauricio Aline Batista. Safety culture and communication about surgical errors from the perspective of the health team. 2019. Cultura de segurança e comunicação sobre erros cirúrgicos na perspectiva da equipe de 
saúde. Revista Gaúcha de Enfermagem;40(spe):e20180192. doi: 10.1590/19831447.2019.20180192, PMID 30652804.

19. Antunes Marques Notaro Karine, dos Reis Corrêa Allana, Tomazoni Andréia,
Patrícia Kuerten Rocha, Bruna Figueiredo Manzo. Safety culture of multidisciplinary teams from neonatal intensive care units of public hospitals Rev. Latino-Am. Enfermagem [Internet];27:e3167. doi: doi: 10.1590/15188345.2849.3167.

Article History: Received: 20-06-2021; Revised: 16-07-2021; Accepted: 02-08-2021

Cite this article: Passos ACB, Santos DB, Fonteles MMF. Patient Safety Culture: from Perception to Assessment. J Young Pharm. 2021;13(3):291-7. 